\title{
Research on Super-high Dumping Sliding Failure Mechanism under Earthquake
}

\author{
Ke-hui Liu ${ }^{1, a}$, Xiao-shun Zhang ${ }^{1, b^{*}}$, Yong-hong Cui ${ }^{1, c}$, Xiao-fei Jing ${ }^{1, d}$, \\ Chang-shu Pan ${ }^{1, e}$ \\ ${ }^{1}$ College of Safety Engineering, Chongqing University of Science \& Technology, Chongqing \\ 401331, China

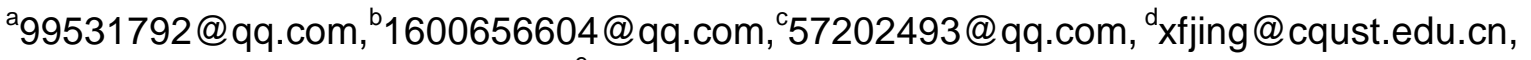 \\ e604241222@qq.com
}

Keywords: Super-high dump; Earthquake; Stability; Failure mechanism; Model test

Abstract. Based on Manaoke gold mine eastern dump, the super-high dump sliding failure mechanism was analysised by numerical simulation and model experiment under earthquake. The results found that: 1.Dump is in basically less stability state under normal work condition, while it is in less stability state under earthquake work condition; 2. Crevasse, forming from dump top to bottom, would cut through the dump and cause it collapsed. The results have directive significance in Super-high dump prevention and control.

\section{Introduction}

Dump is a major hazard of mining enterprises, whose stability influence the normal operation and the safety of lives and property in downstream. It is a lot of disaster losses because of the collapse of dump sloughing control at home and abroad [1]. August 1, 2008 in Taiyuan, Shanxi Province territory Loufan County Taiyuan Iron and Steel (Group) Co., Ltd. Mining Branch Jianshan iron mine particularly significant collapse accident cause 45 people killed and one injured, the direct economic loss of 30.8023 million yuan [2].

The domestic and foreign scholars have done a lot of research on dump in dynamical and static stability [3,9], which has gained the plenteous result. Since 2008, it have happened once 8-magnitude earthquake, four times 7-magnitude earthquakes in China, which shows that we, Chinese mainland, have entered a seismically active period [10]. Moreover, these earthquakes cause great economic losses and casualties [11, 13].

In China, the area of dump and waste dump has reached (1.4 2.0) x $104 \mathrm{~km}^{2}$ and been an annual rate of $340 \mathrm{~km}^{2}$ increasing. While the present reclamation rate is lower, it could only be supported at $6 \%$ from national power [14]. What's worse, the tendency of high bench dump or super-high bench dump is obvious. The increase of dump height will be greatly influenced by earthquake. Therefore, the study of super-high dump stability and failure mode under earthquake is of great importance.

Taking the east golden mine super-high dump of Manaoke as a background, the super-high dump failure mechanism was analysised under earthquake by numerical calculation and model test research method. The results have a certain guiding significance for disaster prevention.

\section{Engineering Situation}

Jiuzhaigou Manaoke gold mine, in the east, tilt angle 45 and a total height of $430 \mathrm{~m}$, reaches 500 million square storage capacities. The accumulation regional is a deep ditch erosion landform area. With a long term of stacking, dump has been relatively high, which appears a larger tensile and cleft failure phenomenon above the upper. (Shown in Figure 1)

\section{Earthquake Similar Model Test}

Test Device. The test device of super-high dump failure mechanism under earthquake is consist of vibration table, model groove, measuring stresses system, digital camera and other components. Model 
groove, in $50 \mathrm{~cm} \times 30 \mathrm{~cm} \times 35 \mathrm{~cm}$ (length $\times$ width $\times$ height), drawing $2 \mathrm{~cm} \times 2 \mathrm{~cm}$ mesh lines, uses a high-strength transparent acrylic plate. In the accumulation process, setting the six displacement tracer on side of dump would be benefit to observe the displacement changes of the dump before and after the earthquake.

Test Procedure and Analysis. It is 8 bolts that fix model groove, used in the model, is fasten by 8 bolts through perform hole to the horizontal vibration table surface. The test instrument is shown in Figure 2.

After the instrument fixed well, vibration table is set at each working time of 30 seconds. Dump surface keep smooth, no crack, and no obvious tumble of soil particles before the earthquake, as shown in figure 3 (A).After the 30 seconds of earthquake, (cycle 1) dump slope surface granules are loosen, rolling larger particles down. Clump at dump bottom move forward obviously, there is an inconspicuous crack in the dump middle, as shown in Figure 3 (B). After 60 seconds of vibration (cycle 2), surface and shallow layer have been produced three certain deep curved bending tensile cracks. Cracks and the top surface has a downtrend, clump at bottom is evidently falling off, as shown in Figure 3(C). After the 90 seconds of earthquake (cycle 3), the length, width and depth of the crack in the upper dump is more obvious than that of the second cycles. The lower dump crack increase to three lines, and clump of the bottom tumble obviously with a phenomenon of collapse, as shown in figure 3 (D).

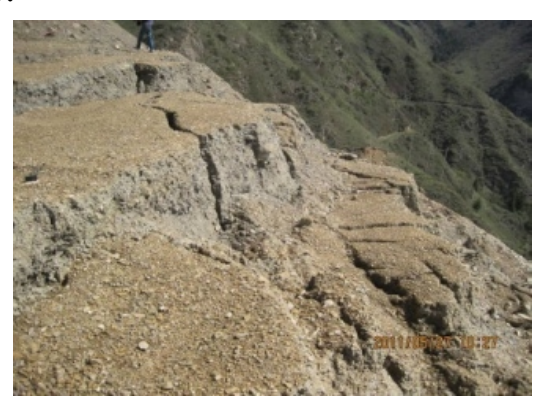

Fig.1 Manaoke ore block east side

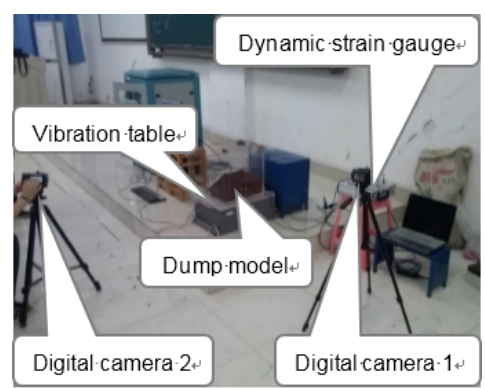

Fig.2 Experimental instrument

of the stacked body tension crack

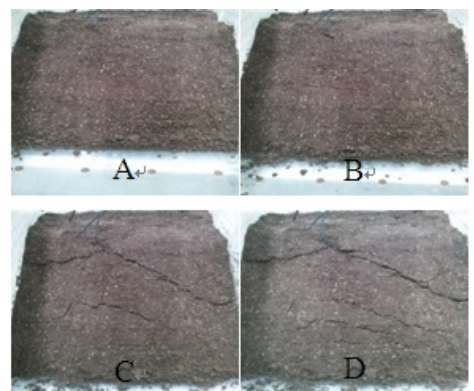

Fig.3 Dump slope change before and after

the earthquake

Displacement Analysis of Dump. Groove grid model as a reference coordinates, Horizontal X-axis, vertical Y axis, Figure 4 (a) and (b) is defined as the coordinates of the second quadrant, ignoring the positive and negative relationships. Dump each point in $\mathrm{X}, \mathrm{Y}$ direction displacement changes as shown in table 1 before and after the earthquake.

Dump internal displacement in $\mathrm{X}, \mathrm{Y}$ directions shows good consistency under earthquake. In the early 6 earthquake displacement points were closed to the tracer dump. The 1 st and 6 st change greatly, as time goes by ,in the lower part of dump, the 2 th, 5th, 6th point displacement in both directions are vary widely, but the overall difference is not too evident. With the continuous influence of the earthquake, the internal of dump generate more displacement. Dump, influenced by its own gravity and technology, appear uneven compaction and stratification in internal. Shear failure in the dump will occurred uneven settlement under seismic loading; it would occur local unrecoverable yield area due to too large shear force in dump internal to accelerate the destruction. Whole dump might slip and destroy when the plastic zone cut through the object.

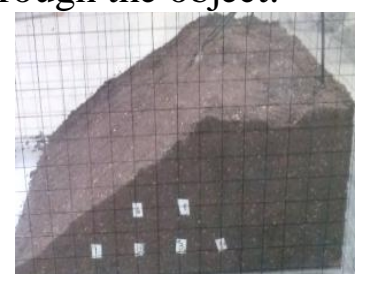

(a) before earthquake

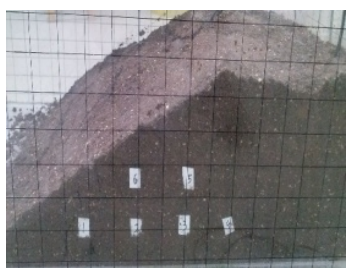

(b) after earthquake

Fig.4 Tracer point displacement earthquake

Analysis of Sliding Destruction Mechanism. Under earthquake in the upper part of the slope appears dump crack, as time increases, on the surface or shallow dump, crack width and depth has increased, as a result of shear failure on the upper part of the larger cracks, the upper soil aggregate 
indirectly apply extrusion to the bottom soil aggregate 1 . While the bottom soil aggregate is squeezed by upper soil aggregate and its gravity and other forces, which bring about new Shear failure in internal that is week and caused new slip mass. With the time increasing influenced by earthquake, which Produce regular destruction in turn. Inside of dump Produce large displacement with same direction of $\mathrm{X}$ Y, the reason why is that Internal of dump arouse Shear failure under earthquake, which further produce Plastic yielding area. When internal plastic area run through, it is most likely to produce integral sliding failure. On the surface of dump shows that the crack has become cracks. With the crack is becoming deeper and wider and produce tendentious potential slide body, In case of prolonged rainfall rainstorm will greatly increase the likelihood of landslides, mudslides and other geological disasters.

TABLE 1 DISPLACEMENT VARIATION OF DUMP

\begin{tabular}{|c|c|c|c|c|c|c|}
\hline $\begin{array}{c}\text { Point } \\
\text { Time }\end{array}$ & 1 & 2 & 3 & 4 & 5 & 6 \\
\hline 0s & $(24,2)$ & $(20,2)$ & $(16,2)$ & $(12,2)$ & $(16,6)$ & $(20,6)$ \\
\hline $30 \mathrm{~s}$ & $(24.4,1.8)$ & $(20.2,1.9)$ & $(16.1,1.8)$ & $(12.1,1.9)$ & $(16.4,5.9)$ & $(20.5,5.8)$ \\
\hline 60s & $(24.6,1.6)$ & $(20.3,1.8)$ & $(16.2,1.7)$ & $(12.2,1.8)$ & $(16.8,5.7)$ & $(20.7,5.5)$ \\
\hline $90 \mathrm{~s}$ & $(25.2,1.5)$ & $(20.7,1.3)$ & $(16.5,1.6)$ & $(12.4,1.7)$ & $(17,5.4)$ & $(20.8,5.4)$ \\
\hline
\end{tabular}

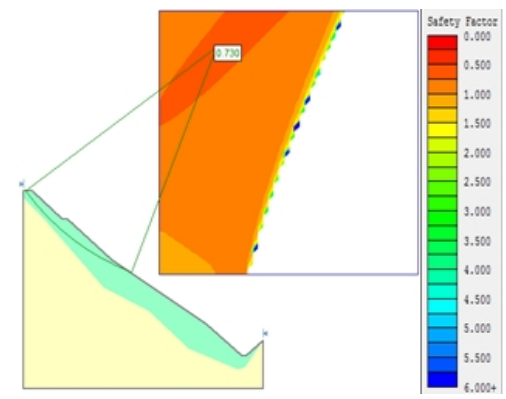

Fig.5 The slope safety factor under the condition of earthquake

\section{Analysis of Dump Stability}

Earthquake or other strong earthquake for the landslide is mainly manifested in two aspects: On the one hand, energytransfer caused by crust earthquake will accelerate the transformation of the landslide potential, It will instantly arouse the imbalance of slope stress and greatly reduced the Shear strength where the slope stability is destroyed suddenly, so, accelerate or cause the landslides occurred. On the other hand, strong earthquake can loosen the rock mass structure; exacerbate the fracture of the earth surface. Furthermore, the surface water is able to infiltrate easily and the shear strength of the rock mass structure slope instability can be reduced. Ultimately, It leads to Slope instability which can form the landslides or accelerate the landslide activity[15] According to "Seismic ground motion parameter zonation map of China" (GB18306-2001), we can knows that the seismic intensity reaches VIII degrees, ground motion peak acceleration of $0.2 \mathrm{~g}$ in the Maonaoke JiuZhaigou SiChuan province. By using SLIDE software, we obtain the results present in Figure 5.

As is demonstrated in Figure 5, the coefficient of dump stability is merely 0.730 under intensity VIII degree earthquakes condition as well as the dump is in less stable state.Thus, under extreme working conditions (for example: earthquakes), dump will generate further tension and shear damage, slope stability deteriorated, and the possibility of the occurrence of unstable failure increased, In case of heavy rainfall or heavy rain may form massive mudslides, will directly threaten people's life and property safety for people who lives in downstream. 


\section{Conclusions}

(1) Based on the limit equilibrium method for dump slope stability analysis, obtain under seismic earthquake condition dump safety factor is 0.730 . It follows that the earthquake conditions dump is less stable; it is prone to slippage failure. In case of rainstorm and other special conditions, it could cause landslides and other geological hazards.

(2) Under earthquake loads, the dump top crack development rapidly. With the earthquake load time increasing, dump deep displacement increases, and in dump internal produce uneven settlement and shear failure. Due to large shear force in the interior of dump generate the local non recoverable region, which accelerated dump destruction. The slip failure could be occurred if the plastic zone runs through the whole dump.

\section{Acknowledgements}

The research reported in this paper has been funded by the National Natural Science Foundation of China (No.51404049); Scientific and Technological Research Program of Chongqing Municipal Education Commission (Grant No. KJ1501328); The Graduate Scientific and Technological Innovation Program of Chong Qing University of Science \& Technology (No.YKJCX2015035); the Interior Research Foundation of Chongqing University of Science \& Technology (CK2014Z12), The authors thank very mush the reviewers for their constructive comments.

\section{References}

[1] Zhen-hua Xie, Na He, Ting-ting Luan. Industrial Safety and Environmental Protection, 2014. 40(2): 73-76. (In Chinese)

[2] Guang-jin Wang, Chun-he Yang, Chao Zhang, Hong-ling Ma, Xiang-yun Kong, Ke- peng Hou. Rock and Soil Mechanics, 2011.32(3): 905-921. (In Chinese)

[3] Hai-bin Wang, Xiao-chun Li, Zi- jun Mi, Zhong-lin Yang. Rock and Soil Mechanics, 2011.32(12): 3672- 3678. (In Chinese)

[4] Xue-bin Xie, Chang-liang Pan. Rock and Soil Mechanics, 2004. 25(2): 287- 291. (In Chinese)

[5] Xu-chun Wang, Xiao-ming Guan, Ming-qing Du, Chen Song. Journal of China Coal Society, 2013.38(2):312-318. (In Chinese)

[6] Yan-ze Li, Peng-fei Chen, Chang-zhi Gao. Opencast Mining Technology, 2014. 6: 25-28. (In Chinese)

[7] Han-peng Liu, Yan-long Mao. Geology and Exploration, 2010.46(4):728-732. (In Chinese)

[8] Feng-chun Zhang, Li Liang, Yu-mai Dai. Metal Mine, 2009. 399:160-164. (In Chinese)

[9] Jun-ping Wang, Xiao Li. China Water Transport, 2013. 13(12):335- 337. (In Chinese)

[10] Information on http://ehsb.hsw.cn/shtml/hsb/20150513/501237.shtml

[11] Ru-shu Wang. Journal of China Three Gorges University (Natural Sciences), 2009. 31(2):1-7. (In Chinese)

[12] Hong-fu Chen, Jun-wu Dai, Bai-tao Sun, Yan-ru Wang, Cang-hai Zhang. Earthquake Engineering and Engineering Dynamics, 2011.31(4):18-25. (In Chinese)

[13] Tong-yan Zheng, Wei Feng, Yi Zheng. World Earthquake Engineering, 2015.31(2): 202-208. (In Chinese)

[14] Yang Cao, Jian-hua Li, Rong-gui Yan, Wen-yu Liu, Tai Zheng. Chinese Journal of Rock Mechanics and Engineering, 2002. 21(12):1858-1862. (In Chinese) 
[15] Hai-tang An, Ping Liu. Journal of Geological Hazards and Environment Preservation, 2010. 21(3): 22-25. (In Chinese) 